\title{
Review: psychological interventions reduce the severity and frequency of chronic pain in children and adolescents
}

\author{
Eccleston C, Morley S, Williams A, et al. Systematic review of randomised controlled trials of psychological therapy for \\ chronic pain in children and adolescents, with a subset meta-analysis of pain relief. Pain 2002;99:157-65.
}

\section{QUESTION: In children and adolescents with chronic pain and associated distress and disability, are psychological interventions effective for reducing the frequency and severity of pain?}

\section{Data sources}

Studies were identified by searching the Cochrane Controlled Trials Register, Medline (1966-99), PsycLIT (1987-99), EMBASE/Excerpta Medica (1980-99), and the Social Sciences indices (1981-99). Bibliographies of relevant articles were reviewed and experts in the field contacted for additional studies.

\section{Study selection}

Studies were selected if they were randomised controlled trials (RCTs) comparing a clearly defined psychological treatment for chronic pain in children and adolescents (even when this treatment was concomitant with other non-psychological treatments given as standard care) with a control condition (including waiting list and self monitoring controls).

\section{Data extraction}

Data were extracted on study setting, sample size, demographic characteristics of the sample and caregivers, therapist characteristics, details of the interventions, study quality, and outcomes. The main outcome was pain experience denoted as Pain Index, a function of the total amount of pain experience derived from patient diary records of frequency, duration, and intensity characteristic of the pain episodes. A reduction in the Pain Index of $\geq 50 \%$ from baseline was equivalent to significant improvement clinically (with subsequent classification of the outcome as improved or unimproved).

\section{Main results}

13 of 18 RCTs that met the selection criteria were included in the meta-analysis. The psychological treatments included relaxation (11 RCTs), relaxation with biofeedback (4 RCTs), cognitive behaviour therapy (9 RCTs), and cognitive behaviour family intervention (1 RCT). 12 RCTs took place in a clinic setting and 6 in a community setting. Treatment contact time was relatively brief with a mean duration of 3 hours (range 45 mins to $9 \mathrm{~h}, 20 \mathrm{mins})$. Meta-analyses were done using a random effects model. More patients in the treatment group than in the control group had a $\geq 50 \%$ reduction in the Pain Index from baseline (table).

\section{Conclusion}

In children and adolescents with chronic pain and associated distress and disability, psychological interventions are effective for reducing the frequency and severity of pain.

Source of funding: no external funding

For correspondence: Dr C Eccleston, University of Bath, Bath, UK.

c.eccleston@bath.ac.uk

A modified version of the abstract appears in Evidence-Based

Nursing.

Psychological interventions $v$ control (wait list, information, and self monitoring) in youth with chronic pain*

\begin{tabular}{|c|c|c|c|c|}
\hline \multirow{2}{*}{$\begin{array}{l}\text { Outcomes at } \geq 3 \\
\text { hours }\end{array}$} & \multicolumn{2}{|c|}{ Weighted event rates } & \multirow[b]{2}{*}{ RBI $(95 \%$ Cl) } & \multirow[b]{2}{*}{ NNT (CI) } \\
\hline & Intervention & Control & & \\
\hline $\begin{array}{l}\geq 50 \% \text { reduction in } \\
\text { pain from baseline }\end{array}$ & $60 \%$ & $15 \%$ & $203 \%$ (103 to 354 ) & 3 (2 to 3 ) \\
\hline
\end{tabular}
effects model.

\section{COMMENTARY}

There is ample evidence that pain is a frequent childhood experience and that childhood symptoms persist into adult life. ${ }^{1}$ Psychological interventions are often recommended for children and adolescents with painful conditions, and reviews have begun to appear that weigh the evidence base for interventions in various types of paediatric pain. These will be important not only for defining effective strategies but also the resources required to treat this population.

The systematic review by Eccleston et al evaluated RCTs of all psychological therapies for all types of chronic pain in childhood. Perhaps inevitably, the results were disappointing, despite an adequate search strategy. The quality of information about the interventions, limited range of measures of variables other than pain (eg, mood, disability, and school attendance), and small size of many studies reduced the analysable data substantially. Nevertheless, this section is useful as an aide-memoire of issues to be addressed in future research in this area.

Ultimately, 13 RCTs provided data suitable for meta-analysis, and all but 1 were treatments for headache-the commonest chronic paediatric pain, but perhaps the one causing least functional disability on a day to day basis. The clear evidence of efficacy of psychological treatments (principally relaxation and cognitive behaviour therapy)-with a number needed to treat of 2.32 for psychological interventions to produce $\geq 50 \%$ relief in pain in 1 additional person relative to control-is valuable information for practitioners and policy makers.

Mary Eminson, MD Royal Bolton Hospital Bolton, UK

1 Fearon P, Hotopf M. Relation between headache in childhood and physical and psychiatric symptoms in adulthood: national birth cohort study. BMJ 2001;322:1145. 